\title{
Local Fatigue Crack Propagation Resistance Relevant To Microstructure Uniquely Developed In A Friction Stirred Ti-6AI-4V Alloy Joint.
}

\author{
M. Okazaki ${ }^{1}$, M. Muzvidziwa² ${ }^{2}$ S. Hirano ${ }^{3}$ \\ ${ }^{1}$ Nagaoka University of Technology 1603-1 Kami-tomioka, Nagaoka, Japan 940-2188 \\ ${ }^{2}$ Hitachi Automotive Systems Co., Atsugi, Japan \\ ${ }^{3}$ Hitachi Research Lab., Hitachi 319-1292, Japan
}

\begin{abstract}
The local resistance to fatigue crack propagation (FCP) in a friction stir welded (FSWed) Ti-6Al-4V alloy joint was investigated, by extracting the miniature CT specimens. Special attention was paid to the role of specific microstructures developed accompanying with a transformation induced lamellar structure (TILS) during the stirring process.

Experimental works indicated that the FCP rates were higher in the stirred zone, especially in the coarse TILS zone which consisted of the prior non-transformed duplex structure and the beta-transformed coarse structure, compared with those in the base metal. These backgrounds were discussed on the basis of fracture mechanics with reference to the measurement of residual stress.
\end{abstract}

\section{INTRODUCTION}

Friction stir welding (FSW) technology is relatively new and offers a number of advantages over conventional welding techniques namely higher process speeds, elimination of filler materials and minimal shrinkage and post weld distortion [1]. The growing interest and potential application of FSW in fabricating titanium components in aerospace and space components entails further work be carried to understand the damage tolerance properties of FSWed joints. Large amount of works have been done to optimise and understand the damage behavior of friction stir welded components [2-8]. The roles of microstructure gradation, hardness distribution and residual stresses have been articulated by a number of 
researchers working on Titanium alloys FSWs [7-10]. It has been shown that a very complicated and inhomogeneous microstructural developments has been unavoidable to have good joint efficiency. In the case of near alpha Ti-6Al-4V (Ti-6-4) alloy, a transformation from hcp to beta structure gets significant, depending on the FSW condition. The development of transformation induced lamellar structures (TILS) was also significant inside of the FSWs in some cases. On the other hand, some references have confirmed that fatigue properties of titanium alloy base materials are closely related to their microstructures and they are not always directly related to static mechanical properties. As an example, Ti-6-4 alloy with a coarse beta structure had higher fatigue crack threshold and higher FCP resistance, than those of the alloy with fine duplex structure, because of surface-induced fatigue crack closure phenomenon which can reduce the FCP driving force [11-13]. Thus, upon optimizing the fatigue design of FSWs of titanium alloys, the questions arise; what is the role of microstructures on FCP? , and what effect(s) should be taken into account regarding the mixed and transformed microstructure frequently appearing in FSW? The roles of TILS has been still unclear.

The purposes of this research are to get basic knowledge on the above questions or dilemma, via exploration on the role of microstructure and the residual stresses in the local FCP resistance of a Ti-6-4 FSWs, where special attention has been paid to the effect of TILS and to the crack propagation near the microstructural interfaces.

\section{Experimental Methods}

\section{FSW}

The starting material in this work was a $7 \mathrm{~mm}$ FSWed joint of a Ti-6Al-4V (Ti-6-4) alloy jointed through a single pass in a butt joint configuration (Fig.1). The following SFW condition were employed; $120 \mathrm{rpm}$ in tool rotation, $15 \mathrm{~mm} / \mathrm{min}$. in welding speed. Here the welding tool made of a Co-based alloy which shoulder diameter was $12 \mathrm{~mm}$ was used [10]. 


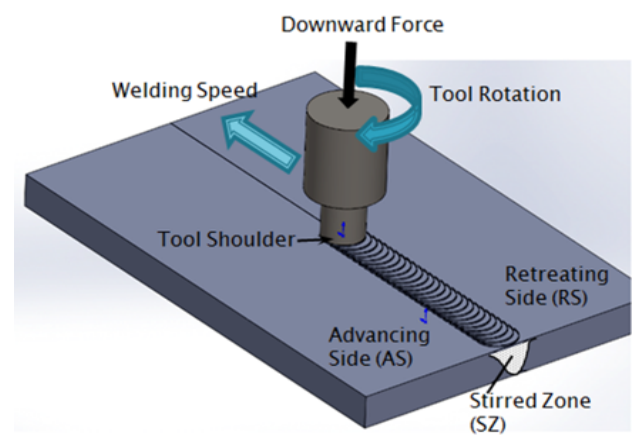

Figure 1 Illustration of FSW [1].

\section{Fatigue Crack propagation tests.}

The local mechanical properties; hardness distribution, yield strength, tensile strength, elongation and strain to rupture, were measured by means of miniature specimens with a

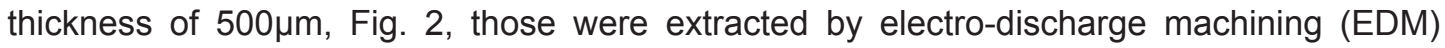
transverse to the weld direction such that the gage length contained the stirred zone. Taking account of the specifically developed inhomogeneous microstructures in the FSWs, as shown later, these measurements were carried by at the multiple areas; typically at $0.3 \mathrm{~mm}$ and $1 \mathrm{~mm}$ site in depth from the top surface of the FSWed plate.

The fatigue crack growth rates in the base metal and welded area were measured by means of compact tension (CT) specimens with initial notches in the base metal and the stirred zone respectively; Fig.2. These CT specimens were precisely extracted from a depth of $0.4 \mathrm{~mm}$ from the top surface by EDM from both the welded area. A series of CT specimens extracted here have such an orientation that the fatigue cracks propagates to the welding, or longitudinal direction, because of thickness limitation of the Ti-6-4 base plate. The fatigue crack propagation (FCP) tests were carried out under ambient conditions, a load ratio, $\mathrm{R}$, of 0.6 and loading frequency of $20 \mathrm{~Hz}$, by means of a servo-electro hydraulic machine. The crack length was monitored and measured through a travelling digital microscope continuously focused on the specimen surface. 


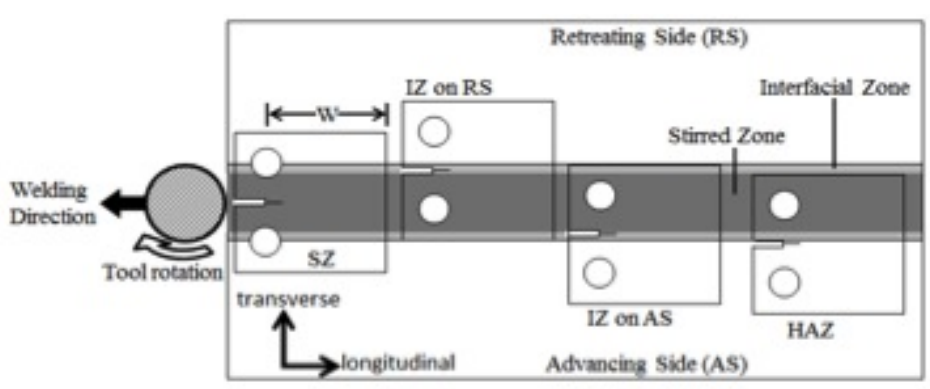

Figure 2 Sites where miniature samples were extracted for fatigue crack propagation tests.

\section{RESULTS AND DISCUSSIONS}

\section{Microstructure, Hardness Distribution and Tensile Strength.}

Figure 3 presents the microstructure developed in the FSWs, those were observed on the plane normal to the longitudinal direction of the original $7 \mathrm{~mm}$ thickness weld. It is found that refinement of the grains in the stirred zone (SZ) was significant, and that there was a noticeable inhomogeneity in grain size and microstructure through the thickness. The former feature could be related to the high lattice strain and temperatures achieved in the material in contact with the tool shoulder, followed by rapid cooling after the welding. With respect to the latter features, the grain sizes were found to be largest within the $S Z$ at a depth of $0.5 \mathrm{~mm}$ from the surface; larger than those at the weld root. It is worthy to note in Figs. 2 and 3 that a microstructurally specific morphological area; or a transformation induced lamellar structure (TILS) consisting of alpha/beta bimodal phases, was developed at the advancing side. This type of microstructure is a direct evidence showing that the local temperature was increased enough during the stirring process so that the transformation of Ti-6-4 alloy was taken place. These characteristic features must be closely related to the low thermal conductivity of titanium alloys and the FSW conditions.

Vickers hardness profiles at different depths across the weld showed that hardness peak appeared in the SZ corresponding to the grain refinement there. The scatter in hardness was significant on the $3 \mathrm{~mm}$ line from the top where the TILS consisting of the prior nontransformed duplex structure and the beta-transformed coarse structure was developed, corresponding to microstructural inhomogeneity in Fig. 3. 


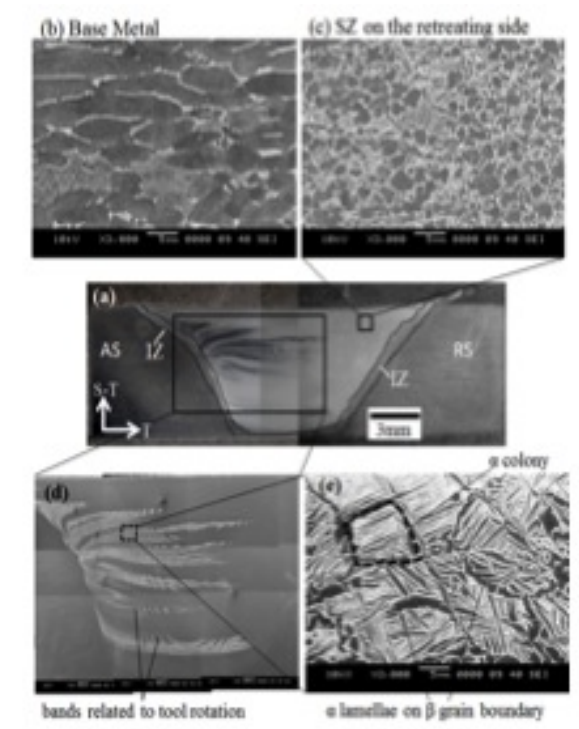

Figure 3 Specific microstructures developed in the FSWs.

\section{Effect of Microstructural inhomogeneity on Local Fatigue Crack Propagation Resistance in FSW}

By means of the miniature sample specimens extracted from the as-FSWed plate without post weld heat treatment, the local fatigue crack propagation resistance was measured and compared between the each crack propagation site in Fig. 4, where the FCP curves are correlated with stress intensity factor range, a traditional fracture mechanics parameter. Comparing with the FCP rates propagating in BM side, all the FCP rates were significantly promoted. It is worthy to note that the rates at the SZ were also accelerated, even when the microstructure refinement was achieved there. The recrystallized equiaxed microstructure in the $S Z$ has been observed to contain significantly refined prior beta grains with alpha colony sizes of one quarter to half the prior beta grain size. In the current work, the prior beta was refined from $13 \mu \mathrm{m}$ in the BM to approximately $5 \mu \mathrm{m}$ thus alpha colony sizes. The FCP behavior was also the case in the IZ site where the grain size was smaller. One of exception was seen at the HAZ site those was free from mechanical stirring but was subjected to thermal history. These trends can be seen almost in common independently on the advancing $(A D)$ and retreating (RT) sides, and independently on the depth from the FSW surface (Fig. 4(a)). Even after giving a post weld heat treatment (PWHT), by $720^{\circ} \mathrm{C} \times 2 \mathrm{hrs}$, the FCP behavior was not changed significantly, as presented in Fig. 4(b). Since the present PWHT condition was enough to release the residual stress, Fig. (b) indicates that the residual stresses played an secondary role in the present work. 


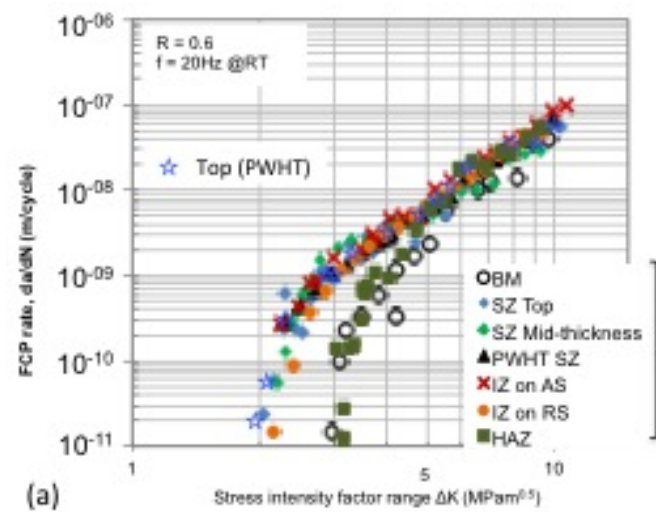

Fig. 4 Local FCP resistance (a) resistance FSWs with and without PWHT (b) Fracture surface upon passing the TILS.

Notes that Fig. 4 gives no more than one of possible aspects on the miscrostructural influences in FCP rates, covering when the crack propagated to the longitudinal direction: i.e., the crack plane was on the transverse-short transverse plane where the TILS partially aligned to the direction parallel to the crack advancing direction. Thus, it is meaningful to investigate the effect of the TILS for the other types of crack propagation plane. For this purpose, the fatigue crack propagation test were carried out for the case when the crack advances to the transverse direction. Here an artificially diffusion bonded blocks which consisted of the beta-transformed and base metal blocks was fabricated by the condition presented in Fig. 5 in laboratory, from which the similar miniature CT specimens were extracted (see an illustration in Fig. 5) 


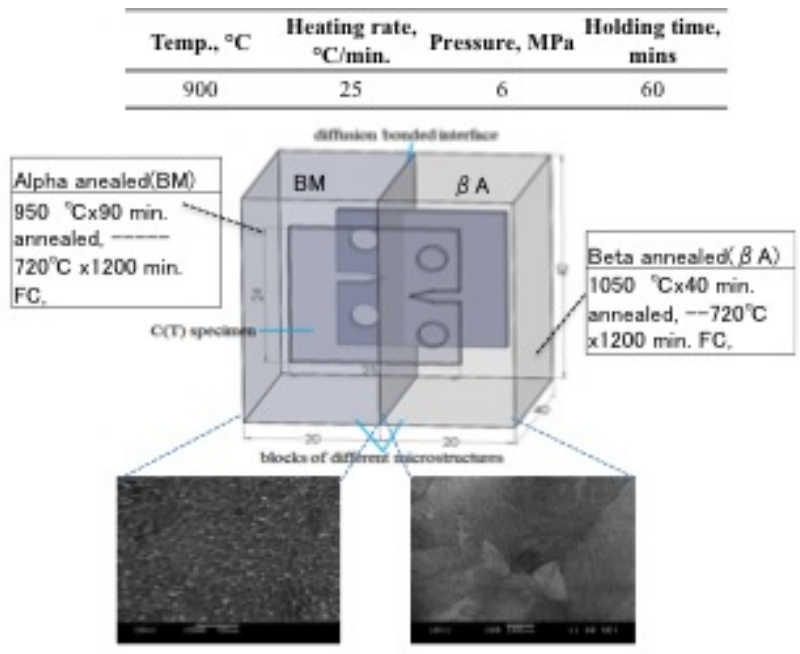

Fig. 5 Diffusion bonding method and condition to construct the artificial interface which consisted of beta-transformed and base metal blocks. The miniature CT specimens were extracted to investigate the FCP behavior near the interface.

Figure 6 expresses the FCP kinetics when the crack advanced near the SZ-BM interface, where the tests were conducted under the so-called DK constant condition (by 5.6 MPam ${ }^{1 / 2}$ ). It is found that the FCP rate decreased as the crack penetrate from the SZ area with beta transformed structure into the BM area. This was also the case when the crack tip propagated in a reversed way. The result of Fig. 6 agrees with the indication from Fig. 6: the microstructural mixture between beta and alpha phases did not lead to beneficial influence in FCP of Ti-6-4 FSWs.

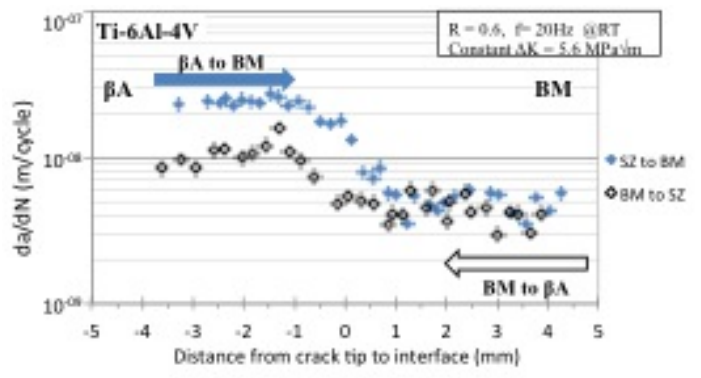

Fig. 6 FCP kinetics near the SZ-BM interface by DK constant test $\left(\Delta \mathrm{K}=5.6 \mathrm{MPam}^{1 / 2}\right)$.

The residual stress may also affect the FCP behavior. The residual stresses in the base metal and the welded area were measure through the $\operatorname{Sin}^{2} \Psi$ method of the X-ray diffraction 
technique. Square-faced plates with dimensions of $30 \mathrm{~mm} \times 30 \mathrm{~mm} \times 4 \mathrm{~mm}$ were extracted from a depth of $0.4 \mathrm{~mm}$ from the top surface of the weld (from the same depth as the CT specimens) using EDM and exposed as-machined. Measurements were carried out along three in-plane directions. The residual stresses measured is presented in Fig. 7 [10]. Whereas a wide distribution of the residual stresses was observed in all the 3 direction, within the weld affected areas the residual stresses were tensile in transverse direction and in compressive in longitudinal direction, respectively. Remind again, the loading direction in the FCP test given in Fig. 4 was transverse to the welding direction. Taking account of the role of stress axiality on stress intensity factor [14], the residual stress field in Fig. 7 is supposed to lead to the following trend: while the FCP rates, especially in the SZ crack, should be accelerated, the degree of acceleration must be relaxed on both the AD and RS sides. This postulation partially support the results of Fig. 4, however, it is not all the case; an indication that the microstructural role was more significant than the residual stress in the present FCP rate.

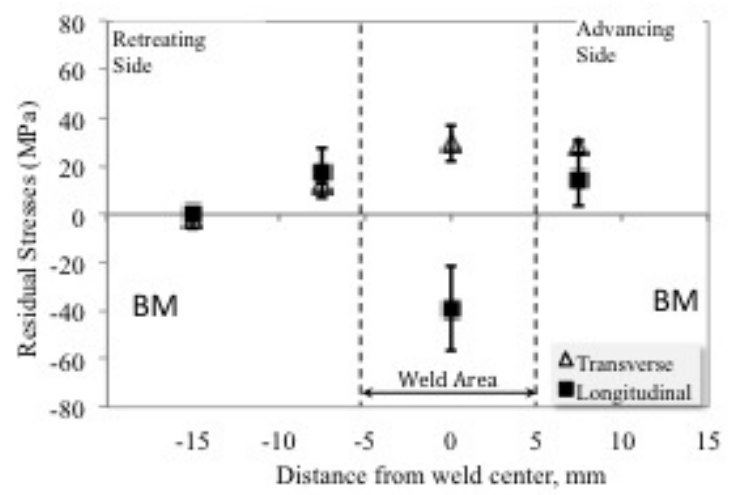

Fig. 7 Residual stress field measured in the FSW without PWHT [10].

\section{Summary}

In this work, the role of the microstructure on the FCP of a FSWed Ti-6-4 was investigated. The main conclusions derived are summarized as follows:

1. A complicated microstructural inhomogeneity was 3-dimensionally developed at the advancing and retreating sides in the Ti-6-4 FSWs, which consisted of the primary alpha phase, and the coarse and fine transformation induced lamellar structures (TILS). 
2. The local FCP rates in the stirred zone and the interfacial zone were higher than those in the base metal and heat affected zone by a few times. The local fatigue crack threshold level was also significantly affected. Here the role of microstructure was more significant than that of residual stress.

3. The TILS developed inside of the FSWs, especially the coarse TILS, had undesirable effect on the FCP, not only in the longitudinal but in the transverse cracks.

\section{Acknowledgements.}

This work is based on results obtained from a future pioneering project commissioned by the New Energy and Industrial Technology Development Organization (NEDO).

\section{References.}

[1] R. S Mishra, M. W. Mahoney (Eds.), Friction Stir Welding and Processing, ASM International, (2007), pp. 1-5.

[2] R. Nandan, T. DebRoy and H.K.D.H Bhadeshia, Progress in Materials Science 53, (2008), pp. 980-1023.

[3] Y. Sato, H. Kokawa, M. Enomoto, and S. Jogan, Metallurgical and Materials Transactions A, Vol.30, (1999), pp. 2429-2437.

[4] R. Brown, Wei Tang and A.P Reynolds., Materials Science and Engineering: A, Vol. 513-514, (2009), pp. 115-121.

[5] R. John, K. V. Jata, and K. Sadananda, International Journal of Fatigue 25, (2003) 939-948

[6] S. Pasta and P. Reynolds, Fatigue and Fracture of Engineering Materials \& Structure 31, (2005), pp. 569-580.

[7] P.D. Edwards and M. Ramulu, Science and Technology of Welding and Joining vol. 14 no. 5, (2009), pp. 476-483. 
[8] A.L Pilchak and J.C. Williams, Metallurgical Transactions vol. 42A, (2011), pp. 1630-1645.

[9] P. S. Pao, R.W. Fonda, H.N. Jones, C.R. Feng, and D.W. Moon, in: Friction Stir Welding and Processing V, R. S. Mishra, M. W. Mahoney (Eds.), TMS, (2009), pp. 29-38.

[10] M.Muzvidziwa , M. Okazaki, K. Suzuki, S. Hirano, Materials Science \&Engineering A652, (2016) pp.59-68.

[11] G. Lutjering, Mat. Sci. and Eng. A243, (1998), pp. 32-45.

[12] S. Suresh, Met. Trans. Vol. 14A, (1983), pp. 2375-2385.

[13] K. Minakawa, A. J. McEvily, Scripta Met., 15, (1981) pp.633-636.

[14] The Soc. Mater. Sci. Japan, Stress Intensity Factor Handbook, ed. Y. Murakami et al, The Soc. Mater. Sci. Japan, (1986). 